SSCL-679

\title{
Activation Concentrations Outside the SSC Accelerator Enclosures
}

\author{
S. Baker, J. Bull, and G. Stapleton
}
Superconducting Super Collider Laboratory*
2275 North Highway 77
Waxahachie, TX 75165

October 1994

*Operated by the Universities Research Association, Inc., for the U.S. Department of Energy under Contract No. DE-AC35-89ER40486. 


\section{DISCLAIMER}

This report was prepared as an account of work sponsored by an agency of the United States Government. Neither the United States Government nor any agency thereof, nor any of their employees, make any warranty, express or implied, or assumes any legal liability or responsibility for the accuracy, completeness, or usefulness of any information, apparatus, product, or process disclosed, or represents that its use would not infringe privately owned rights. Reference herein to any specific commercial product, process, or service by trade name, trademark, manufacturer, or otherwise does not necessarily constitute or imply its endorsement, recommendation, or favoring by the United States Government or any agency thereof. The views and opinions of authors expressed herein do not necessarily state or reflect those of the United States Government or any agency thereof. 


\section{DISCLAIMER}

Portions of this document may be illegible in electronic image products. Images are produced from the best available original document. 


\title{
Activation Concentrations Outside the SSC Accelerator Enclosures
}

\author{
S. Baker, J. Bull, and G. Stapleton
}

\begin{abstract}
Activation of groundwater due to beam loss at the Superconducting Super Collider (SSC) is discussed, with activation criteria and models presented. Estimates are give of maximum beam losses allowed in the various accelerators of the SSC to meet federal drinking water standards, assuming no additional shielding is provided.
\end{abstract}


Activation of groundwater due to routine and accidental beam losses has always been a concern in the design of high energy physics accelerators. In the past, simple well models were developed to demonstrate compliance with federal drinking water standards. These models allowed for the dilution of the induced activity into an individual's annual water usage, and for decay as the radionuclides were transported to the well. Recently, stiffer regulatory requirements have been imposed at some accelerators. At the Continuous Electron Beam Accelerator Facility (CEBAF), where the accelerator is sited below the water table, the Commonwealth of Virginia has required that the groundwater directly outside the accelerator enclosure meet federal drinking water standards. ${ }^{1}$ In recognition of this increased regulatory concern, the Superconducting Super Collider Laboratory (SSCL) is proposing that, for design purposes, the groundwater standards be met at a distance not more than $1 \mathrm{~m}$ from the outside walls of the accelerator enclosures. The purpose of this paper is to present the groundwater activation criteria and model, and to estimate the maximum beam losses allowed in the various accelerators to meet these standards if no additional shielding is provided.

The proposed SSCL groundwater activation model used for the design of facilities requires that the activation concentration in the groundwater located $1 \mathrm{~m}$ outside the accelerator enclosure meet federal drinking water standards. This model is based on the concept of an "activation zone," the region surrounding the enclosure that contains over $99.9 \%$ of the activation produced in the soil and water. In this volume, the average groundwater activation concentration can be calculated and used to demonstrate compliance with the radionuclide concentration limits. Since the induced activation falls off roughly exponentially with the distance into the soil, the average activity concentration in the activation zone can be equated with the activity concentration at a certain distance into the soil. At the SSC, the distance chosen for measurement of the average concentration was $1 \mathrm{~m}$, which corresponds to an activation zone extending approximately $4 \mathrm{~m}$ from the enclosure. The $1 \mathrm{~m}$ distance criterion provides a reasonable clearance from any disturbance produced by the excavation process. It also is conservative, because water movement toward and into the enclosure itself can result in reduced nuclide concentration adjacent to the enclosure and, hence, an average concentration lower than the value calculated. Further conservatism is included in the model in that the calculation is based on saturated activation levels. This period is many years for the radionuclides of concern. Further reduction in activity will occur in any water movement away from the activation zone before saturation is reached.

The total number of atoms per cubic centimeter of a particular isotope produced in soil per incident proton, $n_{i}$, can be written as

$$
n_{i}=S K_{i}
$$

where $S$ is the star density (in stars $/ \mathrm{cm}^{3}$ ) per proton and $K_{i}$, the production factor, is the probability that an atom of radionuclide $i$ will be produced for each star. The star density can be determined with the use of Monte-Carlo cascade codes such as CASIM ${ }^{2}$ and MARS. ${ }^{3}$ The production factor, the ratio of the cross section for production of isotope $i$ to the total nuclear interaction cross section, is dependent on the earth or rock composition. Earlier studies of groundwater activation at accelerators indicate that ${ }^{3} \mathrm{H}$ and ${ }^{22} \mathrm{Na}$ are the only long-lived isotopes that are leachable in significant amounts. ${ }^{4}$ Recently, various rock samples collected from the SSC site have been irradiated to determine the production factors for ${ }^{3} \mathrm{H}$ and ${ }^{22} \mathrm{Na} .{ }^{5}$ Due to the difficulty of measuring the amount of tritium in a solid sample, the production factor for ${ }^{3} \mathrm{H}$ was determined by measuring the amount of tritium in the water collected during the distillation of the original samples. The production factor for both nuclides is lower for chalk than for marl and shale. This conforms to the dip in spallation yield observed by Barbier associated with calcium carbonate. ${ }^{6}$ Compacted fill, since it consists of excavated chalk, also has a low production factor. Table 1 summarizes the production factors for SSC rocks. 
Table 1. Production Factors for SSC Rocks.

\begin{tabular}{|l|c|c|}
\hline \multicolumn{1}{|c|}{ Material } & \multicolumn{2}{c|}{ Production Factor, $\boldsymbol{K}_{\boldsymbol{i}}$ (atoms/star) } \\
\hline & $\mathbf{3}_{\mathbf{H}}$ & $\mathbf{2 2} \mathrm{Na}$ \\
\hline Austin Chalk & 0.029 & 0.005 \\
\hline Eagle Ford Shale & 0.12 & 0.028 \\
\hline Lower Taylor Marl & 0.075 & 0.023 \\
\hline Compacted fill (chalk) & 0.029 & 0.005 \\
\hline
\end{tabular}

If the beam losses have been uniform over many years, the activation rate will have reached equilibrium (saturation) for both nuclides. The specific activity of isotope $i$ in $\mathrm{pCi} / \mathrm{g}$ can then be expressed as

$$
a_{i}=\frac{\dot{N}_{p} S K_{i}}{\rho_{r} \times 0.037 \mathrm{~Bq} / \mathrm{pCi}},
$$

where $\dot{N}_{p}$ is the number of protons lost per second, and $\rho_{r}$ is the wet density of the rock, in $\mathrm{g} / \mathrm{cm}^{3}$. The groundwater activation concentration is then calculated by diluting the specific activity into the amount of water in the rock. The chalk, marl, and shale all have an average wet density of $2.3 \mathrm{~g} / \mathrm{cm}^{3}$, with $12 \%$ of the weight due to the water. ${ }^{7}$ The volume percentage of water in these materials is then $28 \%$; therefore, there is $0.28 \mathrm{~cm}^{3}$ of water per gram of saturated rock. The compacted fill has a density of only $1.85 \mathrm{~g} / \mathrm{cm}^{3}$. If the extra space in fill is replaced by water, then the volume percentage of water in fill is $53 \%\left(0.53 \mathrm{~cm}^{3}\right.$ water per gram of fill).

Not all the activity produced in the rock is picked up and transported by the groundwater; a significant portion of it remains trapped in the rock. The fraction of the activity picked up and carried by the groundwater is called the effective volume fraction leached. This number depends mainly on the chemical properties of the isotopes, the surface area of the rock exposed to the water, and the length of time the water is in contact with the rock. These leachable fractions for Ellis County rock were also determined experimentally and are given in Table 2.5

The expression for the nuclide concentration in water, $C_{i}$, in $\mathrm{pCi} / \mathrm{ml}$ is

$$
C_{i}=\frac{\dot{N}_{p} S K_{i} L_{i}}{\rho_{r} V_{w} \times 0.037 \mathrm{~Bq} / \mathrm{pCi}},
$$

where $L_{i}$ is the effective volume fraction leachable and $V_{w}$ is the volume of water (in ml per gram of rock) used in the leaching process. Therefore, $V_{w}$ is also the volume of water in which the nuclides are diluted. There is no general agreement on the value of $V_{w}$; it varies according to the degree of conservatism one wishes to include in the model. In a previously referenced paper, a volume of water equal in weight to the weight of the rock was used as $V_{w} .5$ This corresponds to the amount of water used to determine the leaching factors in the activation experiments. The current report, however, assumes there is no external source of water, and thus only the water available to leach the radionuclides is in the water-saturated rocks themselves. Therefore the nuclide concentration is determined by diluting the specific activity into the volume of water contained in a gram of rock, taking into account the leachability fraction. This assumption is consistent with the intent of this paper to present a reasonable groundwater activation model that incorporates the most conservative premises. Compared with the other paper, this assumption increases $C_{i}$ by a factor of eight for all rock types and 3.5 for compacted fill. 
Table 2. Effective Volume Fractions Leachable for SSC Rocks.

\begin{tabular}{|l|c|c|c|c|}
\hline \multirow{2}{*}{\multicolumn{1}{|c|}{ Material }} & \multicolumn{4}{c|}{ Effective Volume Fraction Leachable, $L_{i}$} \\
\cline { 2 - 5 } & \multicolumn{3}{|c|}{$\mathbf{3 H}^{22} \mathrm{Na}$} \\
\hline & $1 \mathrm{yr}$ & $1 \mathrm{~h}$ & $1 \mathrm{yr}$ & $1 \mathrm{~h}$ \\
\hline Austin Chalk & 0.66 & 0.44 & 0.071 & 0.013 \\
\hline Eagle Ford Shale & 1.0 & 0.27 & 0.072 & 0.020 \\
\hline Taylor Marl & 1.0 & 0.36 & 0.072 & 0.015 \\
\hline Compacted fill (chalk) & 0.66 & 0.44 & 0.071 & 0.013 \\
\hline
\end{tabular}

Through the Environmental Protection Agency (EPA), the federal government has established standards for community well water systems (defined as 25 users or 15 service outlets). ${ }^{8}$ In DOE Order 5400.5 , DOE has applied these same criteria to private water systems. These requirements specify that the annual effective dose equivalent received by an individual not exceed $4 \mathrm{mrem}$. DOE has published a list of derived concentration guides for radionuclides in water based on an individual ingesting 21 of water per day. ${ }^{9}$ Under these conditions, a person will receive an annual effective dose equivalent of 1 mrem if his drinking water contains either $0.1 \mathrm{pCi} / \mathrm{ml}$ of $22 \mathrm{Na}$ or $20 \mathrm{pCi} / \mathrm{ml}$ of ${ }^{3} \mathrm{H}$. Using these conversion coefficients, the annual effective dose equivalent, $H$, a person receives from tritium and ${ }^{22} \mathrm{Na}$ concentrations in water (symbolized as $C\left({ }^{3} \mathrm{H}\right)$ and $C\left({ }^{22} \mathrm{Na}\right)$, both in $\mathrm{pCi} / \mathrm{ml}$ ) can then be expressed as

$$
H=\frac{C\left({ }^{22} \mathrm{Na}\right)}{0.1 \mathrm{pCi} /(\mathrm{ml} \mathrm{mrem})}+\frac{C\left({ }^{3} \mathrm{H}\right)}{20 \mathrm{pCi} /(\mathrm{ml} \mathrm{mrem})}
$$

In addition, the EPA stipulates that the concentration of tritium in drinking water should not exceed $20 \mathrm{pCi} / \mathrm{ml}$ on average, which effectively limits the tritium portion of the 4-mrem annual limit to $1 \mathrm{mrem}$ using the DOE concentration-to-dose conversion factor.

As mentioned earlier, star densities for each accelerator were calculated using the Monte-Carlo hadronic cascade simulation programs CASIM and MARS12. A similar geometry was used for each accelerator. A magnet, represented by a cylinder of iron with a hole through the center, was placed inside a cylindrical accelerator enclosure. A circular proton beam with a 1-mm Gaussian $\sigma_{r}$ was made to hit the magnet $1 \mathrm{~mm}$ from the outer edge of the aperture. To closer approximate the conditions for each machine, variations in magnet size, tunnel radius, and shielding material were made in the modeled geometry. In addition, the magnets were centered in each enclosure, except the High Energy Booster (HEB) and collider geometry, where the magnet was placed $90 \mathrm{~cm}$ from the center of the tunnel. Table 3 summarizes the geometries used for each machine.

Table 3. Parameters Used in Star Density Calculations.

\begin{tabular}{|c|c|c|c|c|c|c|}
\hline \multicolumn{2}{|c|}{$\begin{array}{l}\text { Accelerator/ } \\
\text { Beam Energy }\end{array}$} & Material & $\begin{array}{c}\text { Magnet Aperture } \\
\text { Size }\end{array}$ & Magnet Size & $\begin{array}{c}\text { Tunnel } \\
\text { Diameter }\end{array}$ & Code \\
\hline Linac & $1 \mathrm{GeV}$ & Fill & $6 \mathrm{~cm}$ diameter & $30 \mathrm{~cm}$ diameter & $240 \mathrm{~cm}$ & MARS \\
\hline LEB & $11 \mathrm{GeV}$ & Fill & $5.8 \mathrm{~cm} \times 8.0 \mathrm{~cm}$ & $54.3 \mathrm{~cm} \times 43 \mathrm{~cm}$ & $400 \mathrm{~cm}$ & CASIM \\
\hline MEB & $200 \mathrm{GeV}$ & Fill/Chalk & $15 \mathrm{~cm} \times 5 \mathrm{~cm}$ & $75 \mathrm{~cm} \times 50 \mathrm{~cm}$ & $250 \mathrm{~cm}$ & CASIM \\
\hline HEB ${ }^{*}$ & $2 \mathrm{TeV}$ & Chalk & $5 \mathrm{~cm}$ diameter & $32.6 \mathrm{~cm}$ diameter & $300 \mathrm{~cm}$ & CASIM \\
\hline SSC & $20 \mathrm{TeV}$ & Chalk & $5 \mathrm{~cm}$ diameter & $27 \mathrm{~cm}$ diameter & $360 \mathrm{~cm}$ & CASIM \\
\hline
\end{tabular}


Shielding is designated for beam backstops and other known loss locations. However, there are presently no provisions to provide extra shielding in the ordinary tunnel sections to reduce groundwater activation. As designed, the linear accelerator (linac), the Low Energy Booster (LEB), and portions of the Medium Energy Booster (MEB) will be built using the cut and cover construction method. These enclosures will have concrete walls at least $30 \mathrm{~cm}$ thick as well as a space approximately $10 \mathrm{~cm}$ thick filled with sand and gravel. Since most of water seeping into this area will be collected by a sump system, this extra thickness can be considered as additional shielding. The remainder of the MEB as well as the HEB and SSC will be bored underground, mostly in chalk. These enclosures will have only a few centimeters of shotcrete covering the enclosure walls. Only the sections of the collider constructed through marl and shale will have a concrete liner, approximately $25 \mathrm{~cm}$ thick.

Equations (3) and (4) can be used to determine the maximum amount of beam that can be lost during a year and still meet the groundwater activation criteria. Figure 1 shows the annual proton loss allowed in the SSC versus distance into the enclosure wall needed to meet the groundwater criteria in chalk, marl, and shale for both the $4 \mathrm{mrem} / \mathrm{yr}$ and the $20 \mathrm{pCi} / \mathrm{ml}$ tritium limits. The proton losses were distributed evenly around the accelerator. As is shown, for the chalk both limits are essentially the same. For the marl, however, the $4 \mathrm{mrem} / \mathrm{yr}$ limit is slightly more restrictive, while for the shale, the $20 \mathrm{pCi} / \mathrm{ml}$ restriction for tritium limit is the limiting case. For shielding purposes, the differences in the two cases are not significant. Figure 2 shows the maximum distributed proton loss allowed in a year for all the accelerators and shielding materials, based on the $4 \mathrm{mrem} / \mathrm{yr}$ dose equivalent limit and $1 \mathrm{yr}$ leaching factors. Figure 3 displays the same for point losses. In each case, the maximum star density for the depth in the shield was used in the calculation. The maximum beam loss permitted to meet the drinking water limits $1 \mathrm{~m}$ from the protective zone is given in Table 4 for distributed losses and in Table 5 for point losses. The annual beam intensity used in these calculations was taken from the SCDR, ${ }^{10}$ using $5 \times 10^{10}$ protons per bunch and high-intensity test beam operating conditions. An operational year of $2 \times 10^{7} \mathrm{~s}$ is assumed.

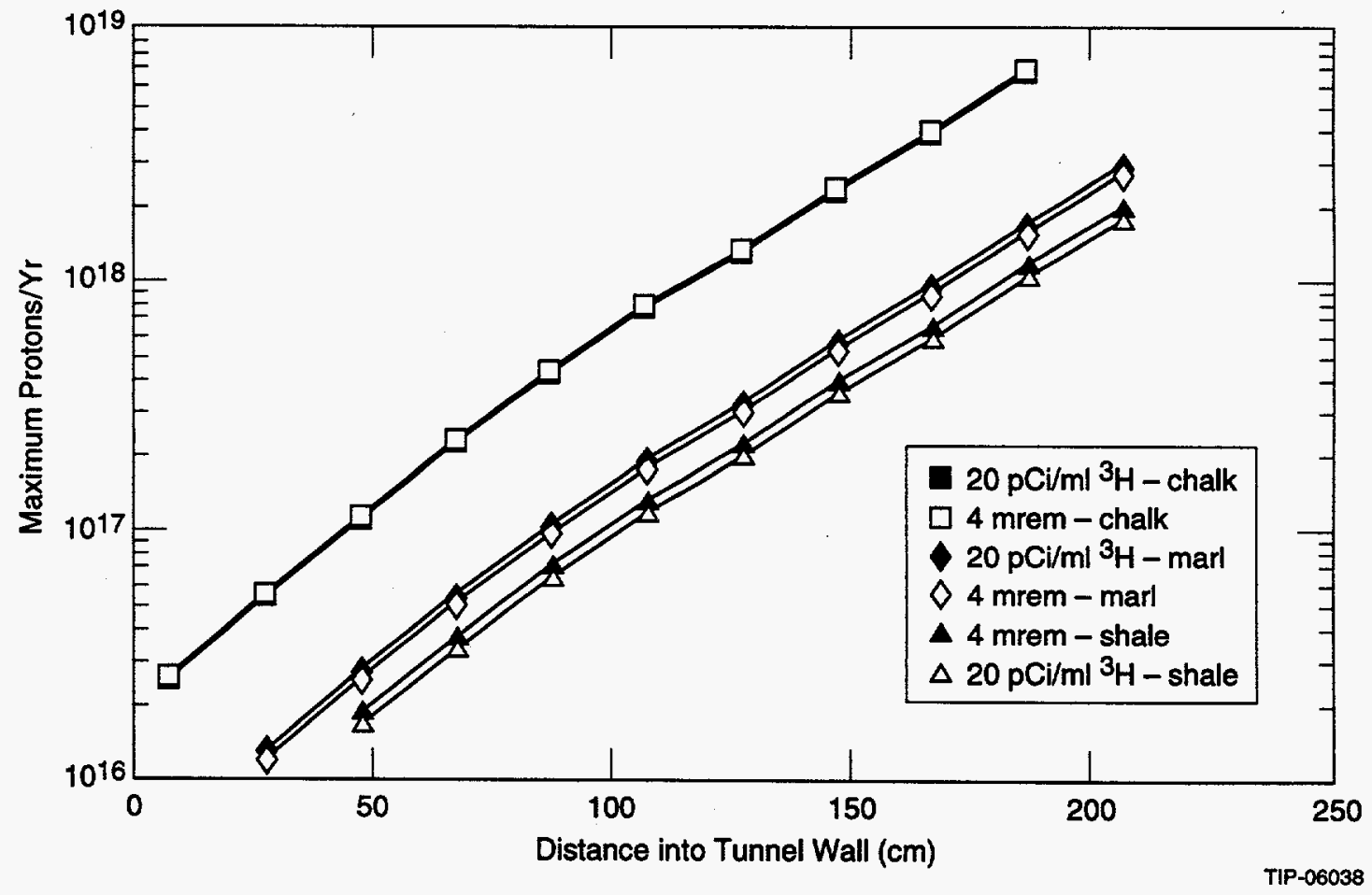

Figure 1. Maximum Number of 20-TeV Protons Lost Distributed Evenly Around the SSC vs. Depth into the Tunnel Wall to Meet the Specific Activation Criteria for All Shielding Materials. 


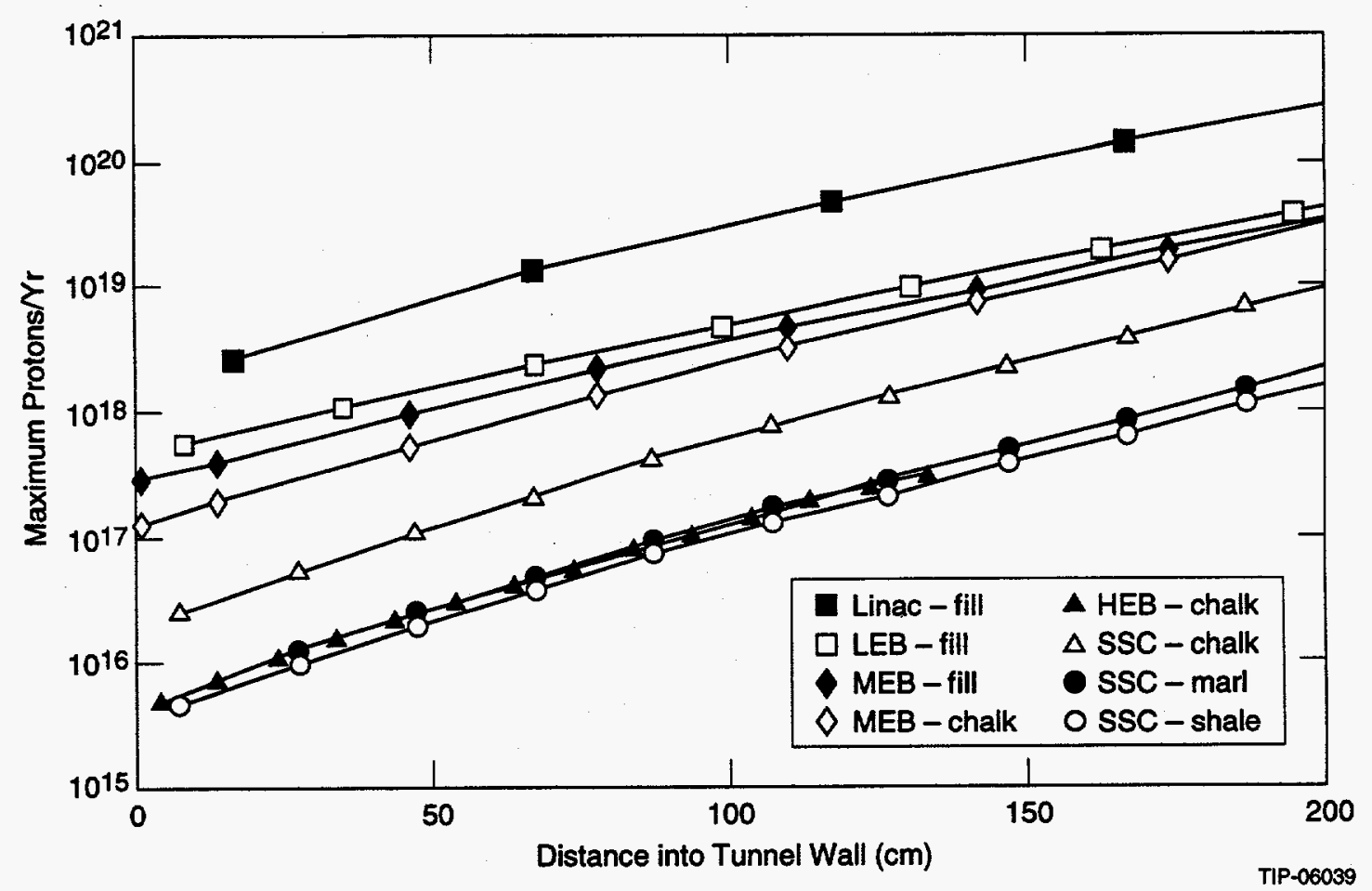

Figure 2. Maximum Number of Protons Lost Distributed Evenly Along the Accelerator vs. Depth into the Tunnel Wall to Meet the Groundwater Activation Criterla.

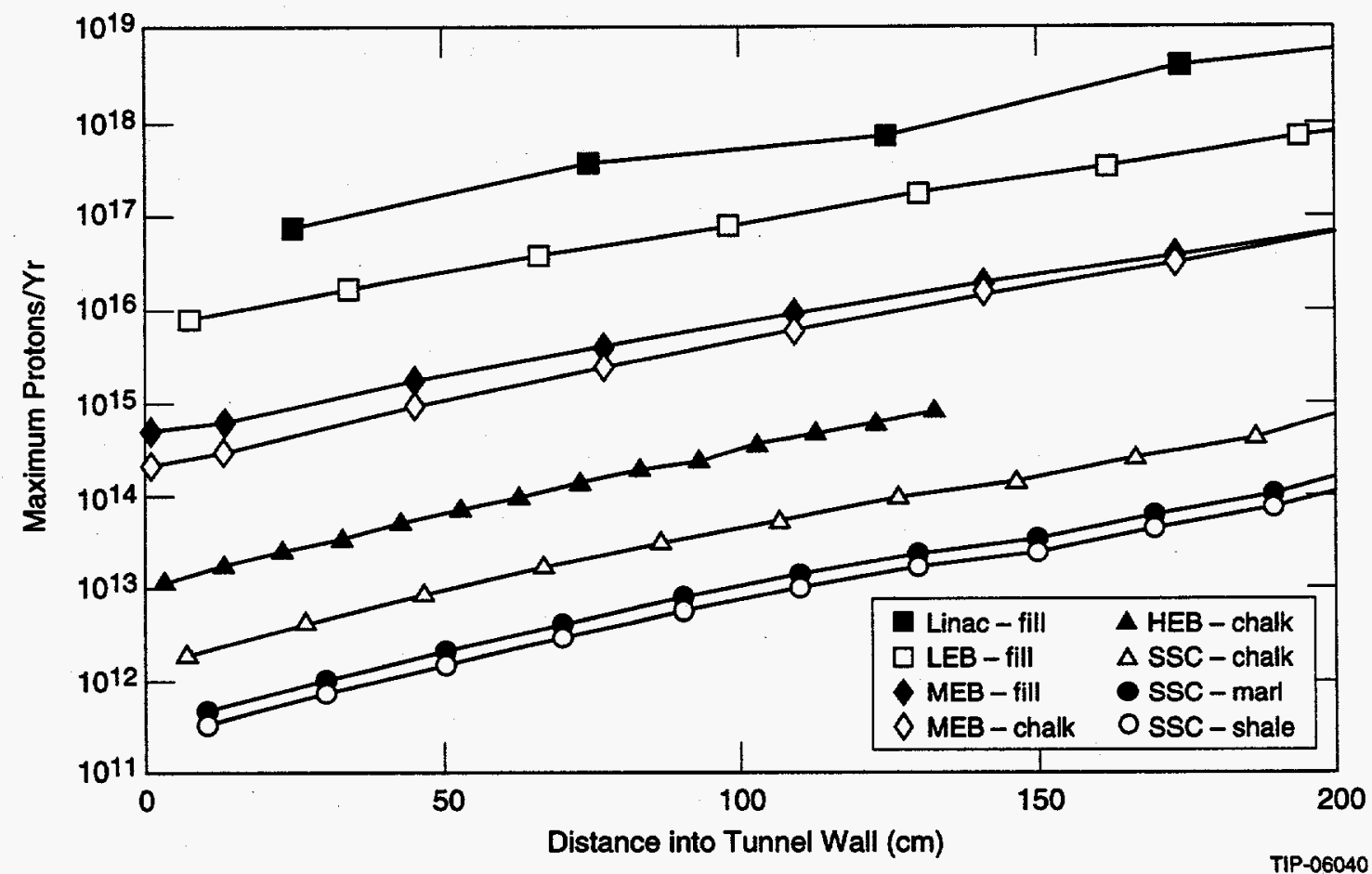

Figure 3. Maximum Number of Protons Lost at a Point vs. Depth into the Tunnel Wall to Meet the Groundwater Activation Criteria. 
Table 4. Allowable Distributed Beam Loss Based on Groundwater Activation.

\begin{tabular}{|c|c|c|c|c|c|c|}
\hline \multicolumn{2}{|c|}{$\begin{array}{c}\text { Accelerator/ } \\
\text { Beam Energy }\end{array}$} & Material & $\begin{array}{c}\text { Enclosure } \\
\text { Wall } \\
\text { Thickness }\end{array}$ & $\begin{array}{c}\text { Maximum Beam Loss Allowed } \\
\text { (Distributed Loss) }\end{array}$ & $\begin{array}{c}\text { Percent Of } \\
\text { Annual Beam }\end{array}$ \\
\hline Linac & $1 \mathrm{GeV}$ & Fill & $40 \mathrm{~cm}$ & $4 \times 10^{10} \mathrm{p} /(\mathrm{m} \cdot \mathrm{s})$ & $7 \times 10^{19} \mathrm{p} / \mathrm{yr}$ & 25 \\
\hline LEB & $11 \mathrm{GeV}$ & Fill & $40 \mathrm{~cm}$ & $6 \times 10^{8} \mathrm{p} /(\mathrm{m} \cdot \mathrm{s})$ & $1 \times 10^{19} \mathrm{p} / \mathrm{yr}$ & 3 \\
\hline MEB & $200 \mathrm{GeV}$ & Fill & $40 \mathrm{~cm}$ & $8 \times 10^{7} \mathrm{p} /(\mathrm{m} \cdot \mathrm{s})$ & $9 \times 10^{18} \mathrm{p} / \mathrm{yr}$ & 3 \\
\hline MEB & $200 \mathrm{GeV}$ & Chalk & $0 \mathrm{~cm}$ & $2 \times 10^{7} \mathrm{p} /(\mathrm{m} \cdot \mathrm{s})$ & $2 \times 10^{18} \mathrm{p} / \mathrm{yr}$ & 0.6 \\
\hline HEB & $2 \mathrm{TeV}$ & Chalk & $0 \mathrm{~cm}$ & $3 \times 10^{5} \mathrm{p} /(\mathrm{m} \cdot \mathrm{s})$ & $1 \times 10^{17} \mathrm{p} / \mathrm{yr}$ & 0.7 \\
\hline SSC & $20 \mathrm{TeV}$ & Chalk & $0 \mathrm{~cm}$ & $2 \times 10^{5} \mathrm{p} /(\mathrm{m} \cdot \mathrm{s})$ & $6 \times 10^{17} \mathrm{p} / \mathrm{yr}$ & $150 \mathrm{per}$ ring \\
\hline SSC & $20 \mathrm{TeV}$ & Marl & $25 \mathrm{~cm}$ & $1 \times 10^{5} \mathrm{p} /(\mathrm{m} \cdot \mathrm{s})$ & $3 \times 10^{17} \mathrm{p} / \mathrm{yr}$ & $75 \mathrm{per}$ ring \\
\hline SSC & $20 \mathrm{TeV}$ & Shale & $25 \mathrm{~cm}$ & $7 \times 10^{4} \mathrm{p} /(\mathrm{m} \cdot \mathrm{s})$ & $2 \times 10^{17} \mathrm{p} / \mathrm{yr}$ & $50 \mathrm{per}$ ring \\
\hline
\end{tabular}

Table 5. Allowable Point Beam Loss Based on Groundwater Activation.

\begin{tabular}{|c|c|c|c|c|c|c|}
\hline \multicolumn{2}{|c|}{$\begin{array}{c}\text { Accelerator/ } \\
\text { Beam Energy }\end{array}$} & Material & $\begin{array}{c}\text { Enclosure } \\
\text { Wall } \\
\text { Thickness }\end{array}$ & $\begin{array}{c}\text { Maximum Beam Loss Allowed } \\
\text { (Point Loss) }\end{array}$ & $\begin{array}{c}\text { Percent Of } \\
\text { Annual Beam }\end{array}$ \\
\hline Linac & $1 \mathrm{GeV}$ & Fill & $40 \mathrm{~cm}$ & $5 \times 10^{10} \mathrm{p} / \mathrm{s}$ & $1 \times 10^{18} \mathrm{p} / \mathrm{yr}$ & 0.3 \\
\hline LEB & $11 \mathrm{GeV}$ & Fill & $40 \mathrm{~cm}$ & $1 \times 10^{10} \mathrm{p} / \mathrm{s}$ & $2 \times 10^{17} \mathrm{p} / \mathrm{yr}$ & 0.06 \\
\hline MEB & $200 \mathrm{GeV}$ & Fill & $40 \mathrm{~cm}$ & $1 \times 10^{9} \mathrm{p} / \mathrm{s}$ & $2 \times 10^{16} \mathrm{p} / \mathrm{yr}$ & 0.006 \\
\hline MEB & $200 \mathrm{GeV}$ & Chalk & $0 \mathrm{~cm}$ & $2 \times 10^{8} \mathrm{p} / \mathrm{s}$ & $5 \times 10^{15} \mathrm{p} / \mathrm{yr}$ & 0.002 \\
\hline HEB & $2 \mathrm{TeV}$ & Chalk & $0 \mathrm{~cm}$ & $1 \times 10^{7} \mathrm{p} / \mathrm{s}$ & $3 \times 10^{14} \mathrm{p} / \mathrm{yr}$ & 0.002 \\
\hline SSC & $20 \mathrm{TeV}$ & Chalk & $0 \mathrm{~cm}$ & $2 \times 10^{6} \mathrm{p} / \mathrm{s}$ & $5 \times 10^{13} \mathrm{p} / \mathrm{yr}$ & 0.001 \\
\hline SSC & $20 \mathrm{TeV}$ & Marl & $25 \mathrm{~cm}$ & $1 \times 10^{6} \mathrm{p} / \mathrm{s}$ & $2 \times 10^{13} \mathrm{p} / \mathrm{yr}$ & 0.0005 \\
\hline SSC & $20 \mathrm{TeV}$ & Shale & $25 \mathrm{~cm}$ & $5 \times 10^{5} \mathrm{p} / \mathrm{s}$ & $1 \times 10^{13} \mathrm{p} / \mathrm{yr}$ & 0.00025 \\
\hline
\end{tabular}

One other area of concern is activation of the groundwater in the case of a beam accident in one of the accelerators. At the SSCL, beam accidents have been defined as the full loss of beam at one point for the resistive magnet accelerators and one machine pulse for the superconducting magnet accelerators. Groundwater activation from a beam accident can also be addressed using the model described above, except that saturation activation will not have been reached. In this case, the specific activation is calculated from the equation

$$
a_{i}=\frac{N_{p} S K_{i}}{\tau_{i} \rho_{r} \times 0.037 \mathrm{~Bq} / \mathrm{pCi}}
$$

where $N_{p}$ is the number of protons lost per accident and $\tau_{i}$ is the mean life of isotope $i$. The nuclide concentration in water, $C_{i}$, in $\mathrm{pCi} / \mathrm{ml}$ can then be expressed as

$$
C_{i}=\frac{N_{p} S K_{i} L_{i}}{\tau_{v} \rho_{r} V_{w} \times 0.037 \mathrm{~Bq} / \mathrm{pCi}}
$$


The dose to an individual is then calculated as above. Figure 4 shows the maximum number of protons lost per accident versus wall thickness for all the accelerators and shielding materials. The limiting restriction is the $4 \mathrm{mrem} / \mathrm{yr}$ dose limit. The maximum number of protons allowed to be lost in a beam accident and still meet the drinking water limits $1 \mathrm{~m}$ from the protective zone is given in Table 6 . As can be seen, the groundwater limits are met in all cases except for the marl in the collider tunnel. In this case, the groundwater activation criteria are met at an additional $25 \mathrm{~cm}$ into the rock from the $1-\mathrm{m}$ boundary.

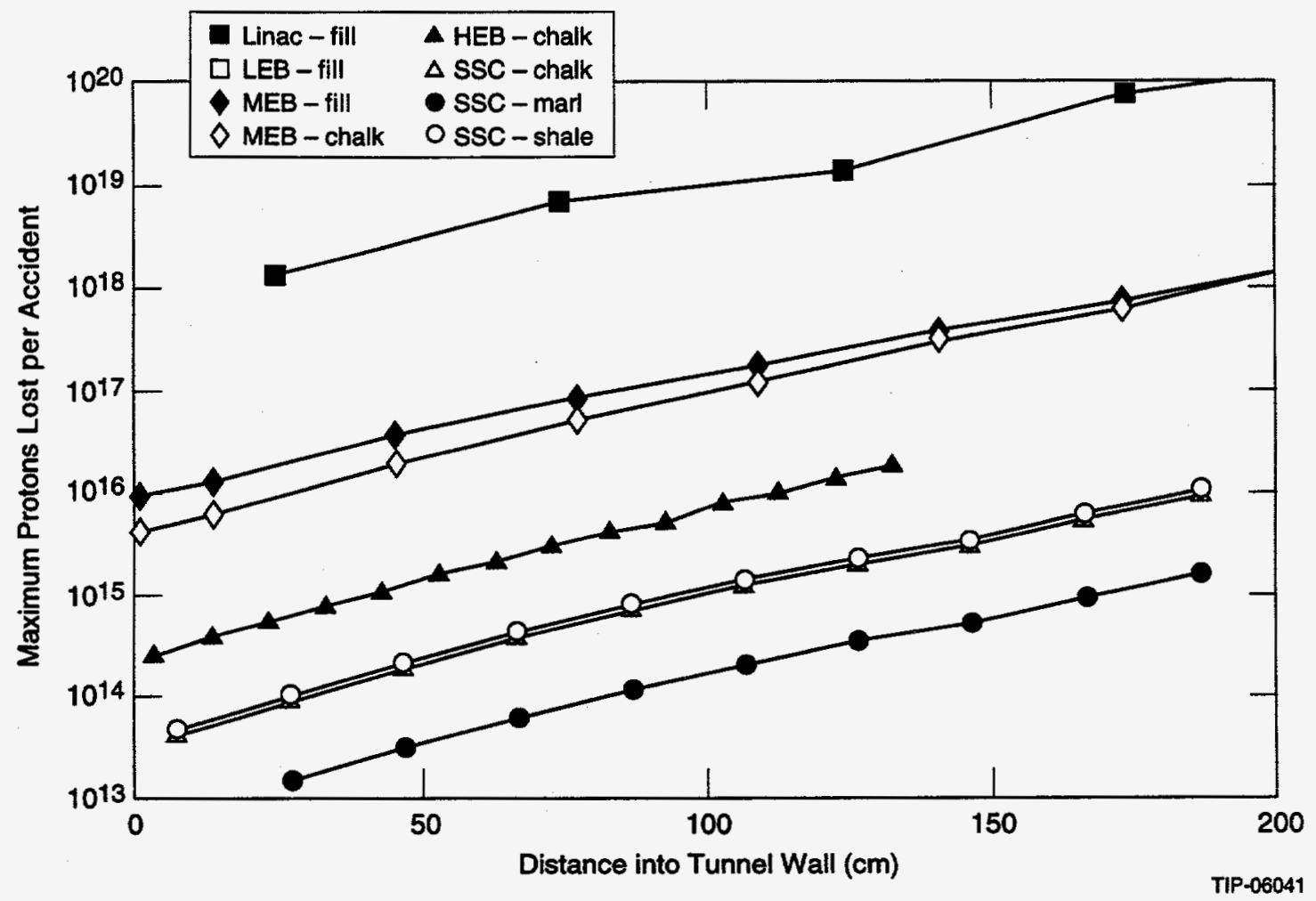

Figure 4. Maximum Number of Protons Lost per Accident vs. Depth into the Tunnel Wall to Meet the Specific Activation Criterla.

Table 6. Allowable Accidental Beam Loss Based on Groundwater Activation.

\begin{tabular}{|c|c|c|c|c|c|}
\hline \multicolumn{2}{|c|}{$\begin{array}{c}\text { Accelerator/ } \\
\text { Beam Energy }\end{array}$} & Material & $\begin{array}{c}\text { Enclosure } \\
\text { Wall } \\
\text { Thickness }\end{array}$ & $\begin{array}{c}\text { Maximum Beam Loss } \\
\text { Allowed (Accidental } \\
\text { Loss) }\end{array}$ & $\begin{array}{c}\text { Percent Of Worst } \\
\text { Case Accident }\end{array}$ \\
\hline Linac & $1 \mathrm{GeV}$ & Fill & $40 \mathrm{~cm}$ & $2 \times 10^{19}$ protons & 900 \\
\hline LEB & $11 \mathrm{GeV}$ & Fill & $40 \mathrm{~cm}$ & $4 \times 10^{18}$ protons & 450 \\
\hline MEB & $200 \mathrm{GeV}$ & Fill & $40 \mathrm{~cm}$ & $3 \times 10^{17}$ protons & 600 \\
\hline MEB & $200 \mathrm{GeV}$ & Chalk & $0 \mathrm{~cm}$ & $1 \times 10^{17}$ protons & 200 \\
\hline HEB & $2 \mathrm{TeV}$ & Chalk & $0 \mathrm{~cm}$ & $7 \times 10^{15}$ protons & 700 \\
\hline SSC & $20 \mathrm{TeV}$ & Chalk & $0 \mathrm{~cm}$ & $1 \times 10^{15}$ protons & 250 \\
\hline SSC & $20 \mathrm{TeV}$ & Marl & $25 \mathrm{~cm}$ & $3 \times 10^{14}$ protons & 75 \\
\hline SSC & $20 \mathrm{TeV}$ & Shale & $25 \mathrm{~cm}$ & $2 \times 10^{15}$ protons & 500 \\
\hline
\end{tabular}


The calculations in this paper include a high degree of conservatism. First, for annual beam losses, this model is based on saturation activity for the nuclides, a level that is reached only after many years of beam loss. If only $1 \mathrm{yr}$ of operation is considered, the groundwater activation concentration is only one fifth of the drinking water limits. After $3.5 \mathrm{yr}$ of operation, the activation concentration will still be less than half the equilibrium value under these maximum loss conditions. In addition, the annual beam intensities used to calculate the beam losses represent a very ambitious test beam program. Initially, the accelerators will not be able to provide such intense beams. By the time these higher intensity beams are produced, the characteristics should be well known for these accelerators, and it should not be difficult to limit typical beam losses to those values listed in Table 3. Also, these calculations are based on the "soda straw model," in which only the water in the ground itself is used to dilute the activity. Any additional water available for leaching will reduce the radionuclide concentration. Experimentally, a lower nuclide concentration has been observed near accelerator enclosures. ${ }^{5,11}$ There will be places along the accelerators where beam will be lost, such as injection and extraction points; these areas can be predicted, and appropriate shielding placed in these areas to protect the groundwater.

\section{ACKNOWLEDGEMENTS}

The authors wish to thank Dave Goss and Van Romero for their extensive review of the text and calculations, and Larry Coulson for his support of this work. 


\section{REFERENCES}

1. Virginia Pollution Abatement Permit No. VPA01001, State Water Control Board, Commonwealth of Virginia, 1989.

2. A. Van Ginneken, "Program to Simulate Transport of Hadronic Cascades in Bulk Matter," FN-272, Fermi National Accelerator Laboratory, 1975.

3. N. I. Mokhov, "The MARS10 Code System: Inclusive Simulation of Hadronic and Electromagnetic Cascades and Muon Transport," FN-509, Fermi National Accelerator Laboratory, 1989.

4. S. Baker, "Soil Activation Measurements at Fermi Laboratory," Proc. Third Environmental Protection Conference ERDA-92, Vol. 1, 1975.

5. S. Baker, J. Bull, and D. Goss, "Leaching of Accelerator-Produced Radionuclides," SSCL Preprint538, May 1994.

6. M. Barbier, Induced Radioactivity, North-Holland Publishing Co., 1969.

7. D. Goss, "Average Density and Composition of Site Materials," Central Design Group internal memo, April 4, 1989.

8. U. S. Code of Federal Regulations 40 CFR 141.

9. DOE Order 5400.5, Chapter III.

10. SSCL, Superconducting Super Collider Site Specific Conceptual Design, SSCL-SR-1056, July 1990.

11. S. Baker, "Fermilab Soil Activation Experience," Proceedings of the Fifth DOE Environmental Protection Information Meeting, DOE Publ. CONF-841187, 1985.SCL. 